BuletinIlmiah Math, Stat, danTerapannya (Bimaster)

Volume 08, No. 2 (2019), hal 349-356.

\title{
ESTIMASI PARAMETER MODEL SURVIVAL DISTRIBUSI PARETO - GAMMA DENGAN METODE BAYESIAN LINEX LOSS FUNCTION
}

\author{
Mega Putri, Shantika Martha, Setyo Wira Rizki \\ INTISARI
}

\begin{abstract}
Data survival merupakan data yang menunjukkan waktu suatu individu atau objek dapat bertahan hidup hingga terjadinya suatu kejadian tertentu. Data dikatakan tersensor apabila data yang diamati tidak lengkap karena hilangnya objek penelitian atau sampai akhir penelitian objek tersebut belum mengalami suatu kejadian tertentu. Tujuan dari penelitian ini adalah menentukan estimasi parameter model survival yang berdistribusi Pareto pada data tersensor dengan metode Bayesian LINEX Loss Function menggunakan prior Gamma. Data yang digunakan adalah data sekunder pasien kanker paru-paru dari penelitian yang dilakukan oleh Kalbfleisch dan Prentice pada tahun 1980. Berdasarkan hasil estimasi metode Bayesian LINEX Loss Function untuk studi kasus penderita kanker paru-paru dapat diketahui peluang seorang penderita kanker paru-paru untuk bertahan hidup semakin lama semakin kecil (mendekati nol), hingga akhirnya mengalami kematian. Nilai MAPE yang diperoleh dari fungsi Survival distribusi Pareto dengan pendekatan Bayesian LINEX Loss Function adalah sebesar 19,66\%. Hal ini berarti bahwa metode Bayesian LINEX Loss Function memiliki kemampuan peramalan yang baik dalam mengestimasi peluang hidup pasien penderita kanker paru-paru.
\end{abstract}

Kata Kunci : Distribusi Pareto, Bayesian, LINEX Loss Function, MAPE.

\section{PENDAHULUAN}

Analisis survival merupakan prosedur statistika yang digunakan untuk menganalisis data dimana variabel yang diperhatikan adalah jangka waktu dari awal pengamatan sampai suatu event terjadi dengan melihat variabel-variabel yang mempengaruhi event tersebut[1]. Jangka waktu dari awal pengamatan sampai terjadinya suatu event disebut dengan waktu survival yang biasanya diukur dalam hari, minggu, bulan maupun tahun. Pada analisis survival, data survival dibedakan menjadi dua jenis yaitu data tersensor dan data tidak tersensor. Data tersensor adalah data yang tidak bisa diamati secara keseluruhan karena terdapat subyek pengamatan yang hilang atau tidak lengkap atau sampai akhir penelitian subjek tersebut belum mengalami kejadian tertentu. Data dikatakan tidak tersensor apabila semua objek penelitian atau unit data yang diteliti mati atau gagal. Terdapat beberapa metode yang digunakan untuk menganalisis data survival. Metode-metode tersebut antara lain metode parametrik dan metode nonparametrik. Salah satu model parametrik adalah distribusi Pareto.

Permasalahan utama dalam metode Bayesian adalah menentukan prior. Adapun distribusi prior yang digunakan dalam pengamatan ini adalah prior gamma, karena distribusi gamma merupakan prior sekawan bisa juga disebut sebagai prior informatif untuk distribusi Pareto. Informasi dalam distribusi prior dikombinasikan dengan fungsi likelihood dan hasilnya dinyatakan dalam bentuk distribusi yang disebut distribusi posterior. Distribusi posterior selanjutnya menjadi dasar untuk inferensi di dalam metode Bayesian.

Terdapat beberapa pendekatan dalam metode Bayesian yang dapat digunakan untuk mengestimasi parameter antara lain General Non-informatif Prior, Lindley Aproximation, General Entroppy Loss Function (GELF), dan Squared Error Loss Function (SELF), Linear Exponential Loss Function (LINEX Loss Function). Metode Bayesian LINEX adalah metode loss function yang paling umum digunakan untuk estimasi Bayesian[2]. 
Penelitian ini bertujuan untuk menentukan estimasi parameter model survival berdistribusi Pareto prior Gamma pada data tersensor dengan pendekatan Bayesian Linear Exponential Loss Function (LINEX Loss Function). Nilai estimasi yang diperoleh digunakan untuk mengestimasi parameter model survival berdistribusi Pareto menggunakan prior Gamma pada kasus penderita kanker paruparu. Distribusi sampel yang digabungkan dengan distribusi prior akan menghasilkan distribusi Posterior yang selanjutnya akan menjadi dasar dalam metode Bayesian. Distribusi Posterior menyatakan derajat keyakinan seseorang mengenai suatu parameter setelah sampel diamati[3].

Data yang digunakan adalah data waktu survival dengan penyensoran berupa data kanker paru-paru yang diperoleh dari program R. Distribusi yang digunakan untuk model survival data tersensor adalah distribusi Pareto. Langkah pertama yang dilakukan yaitu data kanker paru-paru yang diperoleh selanjutnya diuji dengan menggunakan Kolmogorov-Smirnov sehingga diketahui bahwa data tersebut berdistribusi Pareto. Langkah selanjutnya adalah menentukan fungsi distribusi kumulatif, fungsi survival dan fungsi hazard dari distribusi Pareto. Kemudian menentukan fungsi likelihood untuk data tersensor. Setelah diperoleh fungsi likelihood, selanjutnya merumuskan distribusi prior dan posterior untuk metode Bayesian. Metode estimasi yang digunakan pada penelitian ini yaitu metode Bayesian LINEX Loss Function. Setelah itu menentukan estimasi parameter dari metode Bayesian LINEX Loss Function. Kemudian, melakukan proses perhitungan fungsi survival dari hasil estimasi Bayesian LINEX Loss Function. Langkah terakhir ialah menghitung hasil estimasi Bayesian LINEX Loss Function dan menerapkan pada kasus penderita kanker paru-paru.

\section{DISTRIBUSI SURVIVAL}

Distribusi survival dapat dinyatakan dengan tiga fungsi yaitu, fungsi kepadatan peluang, fungsi bertahan hidup (fungsi survival), dan fungsi hazard. Waktu survival merupakan variabel random nonnegatif yang mewaliki waktu survival dari individu-individu dalam populasi yang merupakan variabel random kontinu dalam interval $[0, \infty)$ atau waktu survival pada waktu $t$ dengan $t \geq 0$ [4].

\section{Fungsi Kepadatan Peluang (Probability Density Function)}

Fungsi Kepadatan Peluang atau Probability Density Function (PDF) adalah peluang suatu individu akan meninggal atau mengalami kejadian sesaat dalam interval waktu $t$ sampai $(t+\Delta t)$. Rumus dari Fungsi kepadatan peluang $(t)$ adalah sebagai berikut:

$$
f(t)=\lim _{\Delta t \rightarrow 0}\left[\frac{P(t<T<(t+\Delta t))}{\Delta t}\right]=\lim _{\Delta t \rightarrow 0}\left[\frac{F(t+\Delta t)-F(t)}{\Delta t}\right]
$$

Jika T merupakan variabel acak positif pada interval $[0, \infty)$, maka $F(t)$ merupakan fungsi distribusi kumulatif kontinu dari $T$ [5]. Sehingga peluang suatu individu mengalami kejadian kurang dari sama dengan waktu t yang dapat didefinisikan sebagai berikut:

$$
F(t)=P(T \leq t)=\int_{0}^{t} f(t) d t
$$

\section{Fungsi Survival}

Fungsi survival $S(t)$ didefinisikan sebagai peluang suatu individu dapat bertahan hidup dengan waktu survival sampai dengan waktu $t$ dengan $(t \geq 0)$ yaitu sebagai berikut:

$$
S(t)=1-P(T \leq t)=1-F(t), t \geq 0
$$

\section{Fungsi Hazard}

Fungsi hazard $h(t)$ didefinisikan sebagai kelajuan suatu individu mengalami kejadian dalam interval waktu dari $t$ sampai $(t+\Delta t)$ dengan syarat individu tersebut masih bertahan hidup sampai dengan waktu $t$. Fungsi Hazard dinyatakan sebagai berkut:

$$
h(t)=\lim _{\Delta t \rightarrow 0}\left[\frac{P(t \leq T<(t+\Delta t) \mid T \geq t)}{\Delta t}\right]
$$


Untuk $T$ merupakan suatu variabel random dan $f(t)$ merupakan fungsi kepadatan peluang dari $T$, diperoleh persamaan untuk fungsi hazard sebagai berikut:

$$
h(t)=\frac{f(t)}{S(t)} \quad S(t) \neq 0
$$

\section{DISTRIBUSI PARETO}

Distribusi pareto berasal dari nama seorang ekonom yaitu Vilfredo Pareto (1848-1923) yang mengamati bahwa $80 \%$ kekayaan di Milan dimiliki oleh hanya $20 \%$ dari penduduknya. Oleh karena itu, hukum ini dikenal juga sebagai hukum 20/80[6]. Distribusi pareto sering dipakai pada persoalan uji hidup, seperti waktu sampai rusak atau umur suatu komponen yang diukur dari suatu waktu tertentu sampai rusak[7]. Fungsi densitas distribusi Pareto adalah:

$$
f(t)=\frac{\alpha \theta^{\alpha}}{\mathrm{t}^{\alpha+1}}
$$

Fungsi distribusi kumulatif untuk distribusi Pareto adalah:

$$
F(t)=1-\left(\frac{\theta}{t}\right)^{\alpha}
$$

Fungsi survival dari distribusi Pareto adalah sebagai berikut:

$$
S(t)=\left(\frac{\theta}{t}\right)^{\alpha}
$$

Fungsi hazard dari distribusi Pareto adalah sebagai berikut:

$$
h(t)=\frac{\alpha}{t}
$$

\section{METODE BAYESIAN}

Pada metode Bayesian, parameter dipandang sebagai variabel random yang memiliki distribusi yang disebut dengan distribusi prior. Dari distribusi prior, selanjutnya dapat ditentukan distribusi posterior yang merupakan gabungan dari fungsi likelihood dan distribusi prior. Hasil dari posterior yang didapat ialah dasar untuk memperoleh estimasi metode Bayesian. Berikut adalah langkahlangkah yang dilakukan dalam analisis metode Bayesian yaitu:

\section{Menentukan fungsi likelihood untuk data tersensor}

Fungsi likehood pada data tersensor dari data pengamatan $\left(t_{i}, \delta_{i}\right)$, dengan $i=1,2, \ldots, n$ adalah:

$$
L(\theta)=\prod_{i-1}^{n}\left[f\left(t_{i}\right)\right]^{\delta_{i}}\left[S\left(t_{i}\right)\right]^{1-\delta_{i}}
$$

Dengan $\delta_{i}$ adalah indikator penyensoran, bernilai 1 jika data tersensor dan bernilai 0 jika tidak tersensor. Nilai $t_{i}$ diperoleh dari $\min \left(T_{i}, C_{i}\right) i=1,2, \ldots, n$, dengan $T_{i}$ adalah waktu hidup individu ke $i$ dengan $i=1,2, \ldots, n$. Sehingga fungsi likelihood dari distribusi Pareto untuk data tersensor memiliki bentuk sebagai berikut:

$$
\begin{aligned}
L\left(t_{i} ; \alpha ; \theta ; \delta_{i}\right) & =\prod_{i=1}^{n}\left[\frac{\alpha \theta^{\alpha}}{t_{i}^{\alpha+1}}\right]^{\delta_{i}}\left[\left(\frac{\theta}{t_{i}}\right)^{\alpha}\right]^{1-\delta_{i}} \\
& =\frac{\theta^{n \alpha} \alpha^{\Sigma_{i=1}^{n} \delta_{i}}}{\prod_{i=1}^{n}\left(t_{i}\right)^{\delta_{i}+\alpha}}
\end{aligned}
$$




\section{Pemilihan Distribusi Prior}

Dalam metode Bayesian, ketika suatu populasi mengikuti distribusi tertentu dengan suatu parameter didalamnya yang dalam hal ini dimisalkan dengan $\theta$, maka parameter $\theta$ mengikuti suatu distribusi peluang yang disebut distribusi prior. Dalam kasus ini, peneliti menggunakan distribusi Gamma sebagai distribusi prior untuk distribusi Pareto dengan parameter $\theta$ dimana $0<\theta<\infty$. Berikut adalah prior gamma berdistribusi Pareto.

$$
f(\theta) \quad=\frac{B^{A}}{\Gamma(A)} \theta^{A-1} e^{-B \theta}
$$

dimana pada prior gamma distribusi pareto mempunyai dua variabel yaitu $(\alpha, \theta)$ dengan $\alpha$ merupakan konstanta dan $\theta$ merupakan parameternya.

\section{Pembentukan Distribusi Posterior}

Distribusi posterior diperoleh dari penggabungan prior dengan informasi sampel yang diperoleh dari fungsi Likelihood. Sehingga distribusi posterior gamma dinyatakan sebagai berikut:

$$
f\left(\theta \mid t_{i}\right)=\frac{f(\theta) f\left(t_{i} \mid \theta\right)}{\int_{0}^{\infty} f(\theta) f\left(t_{i} \mid \theta\right) d \theta}
$$

Dengan $f\left(\theta \mid t_{i}\right)$ menunjukan distribusi posterior, $f(\theta)$ merupakan distribusi prior, dan $f\left(t_{i} \mid \theta\right)$ merupakan fungsi likelihood. Berdasarkan persamaan (10) dan (11), maka fungsi kepadatan peluang distribusi posterior Gamma sebagai berikut:

$$
f\left(\theta \mid t_{i}\right)=\frac{\theta^{A+n \alpha-1} e^{-B \theta} B^{A+n \alpha}}{\Gamma(A+n \alpha)}
$$

\section{ESTIMASI PARAMETER METODE BAYESIAN LINEX}

Estimasi parameter yang digunakan dalam Linear Exponential Loss Function (LINEX Loss Function) yang mana dimisalkan dengan $\hat{\theta}_{B L}$ dapat didefinisikan sebagai berikut:

$$
\hat{\theta}_{B L}=-\frac{1}{c} \ln \left[E\left(e^{-c \theta}\right)\right]
$$

Dengan $\hat{\theta}_{B L}$ digunakan sebagai estimator. Berdasarkan persamaan (13) maka estimasi parameter dengan metode Bayesian LINEX Loss Function adalah sebagai berikut:

$$
E\left(e^{-c \theta}\right)=B^{A+n \alpha}(B+c)^{-A-n \alpha}
$$

maka estimasi parameter dengan metode Bayesian LINEX Loss Function adalah sebagai berikut:

$$
\widehat{\theta}_{B L}=-\frac{1}{c}(A+n \alpha \ln B-A \ln (B+c)-n \alpha \ln (B+c))
$$

Sehingga diperoleh estimasi fungsi survival dan fungsi hazard dengan Metode Bayesian LINEX Loss Function dari distribusi Pareto pada data tersensor dengan distribusi Posterior Gamma adalah:

$$
\begin{aligned}
\hat{S}_{B L}\left(t_{i} ; \hat{\theta}_{B L}\right) & =\left(\frac{-\frac{1}{c}(A+n \alpha \ln B-A \ln (B+c)-n \alpha \ln (B+c))}{t}\right)^{\alpha} \\
\hat{h}_{B L}\left(t_{i} ; \hat{\theta}_{B L}\right) & =\frac{\alpha}{t}
\end{aligned}
$$

\section{STUDI KASUS}

Studi kasus yang digunakan adalah data waktu survival 71 pasien penderita kanker paru-paru. Data tersebut diambil dari penelitian yang dilakukan oleh Kalbfleisch dan Prentice pada tahun 1980. Penelitian ini bertujuan untuk menentukan estimasi parameter model survival berdistribusi ParetoGamma pada data tersensor. Selanjutnya dilakukan uji distribusi data untuk mengetahui data berdistribusi Pareto atau tidak. Kemudian mengestimasi parameter menggunakan metode Bayesian 
LINEX Loss Function untuk data 71 pasien penderita kanker paru-paru. Pemaparan selengkapnya adalah sebagai berikut:

\section{Uji Distribusi Data}

Uji kecocokan (Goodness of Fit) digunakan untuk mengetahui ada tidaknya kecocokan model yang diasumsikan atau apakah suatu variabel bisa didekati menggunakan suatu distribusi atau tidak. Taraf nyata yang digunakan adalah $\alpha_{0}=5 \%=0,05$. Dalam menentukan keputusan akhir untuk menolak atau menerima $H_{0}$ didasarkan pada daerah kritis $\alpha_{0}$ dengan nilai $p$-value yang mendukung suatu uji dalam bentuk peluang, jika nilai $p$-value $\leq \alpha_{0}$ maka $H_{0}$ ditolak dan $H_{1}$ diterima.

Tabel 1 Hasil Uji Kolmogorov-Smirnov menggunakan EasyFit

\begin{tabular}{|l|l|}
\hline \multicolumn{2}{|l|}{ Pareto } \\
\hline Kolmogorov-Smirnov \\
\hline P-Value & 0,19547 \\
\hline
\end{tabular}

Dari Tabel 1 terlihat bahwa nilai $P$-value pada Uji Kolmogorov-Smirnov untuk distribusi Pareto adalah 0,19547 , artinya $P$-value $>0,05$ sehingga $H_{0}$ diterima dan dapat ditarik kesimpulan bahwa data berdistribusi Pareto.

\section{Estimasi Parameter Metode Bayesian LINEX Loss Function pada Model Survival untuk Data Tersensor Berdistribusi Pareto}

Dari data kasus pasien penderita kanker paru-paru dengan menggunakan program $\mathrm{R}$, didapat nilai $\alpha=1,187646, \theta=72$, parameter A (shape $)=2,373378$, parameter B $($ rate $)=88,21829, \mathrm{c}=0,1$, dan $\hat{\theta}_{B L}=83,571338$ atau dibulatkan menjadi 83,57 dengan syarat $t>\theta$. Sehingga diperoleh masingmasing grafik fungsi survival distribusi pareto dan fungsi survival yang sudah diestimasi dengan metode Bayesian LINEX Loss Function sebagai berikut:

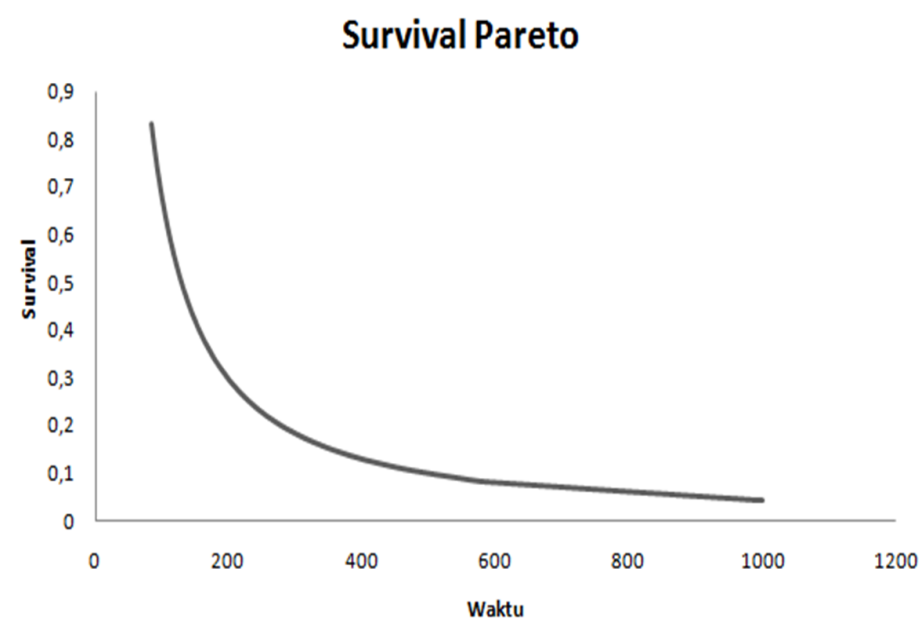

Gambar 1 Grafik fungsi survival distribusi Pareto 


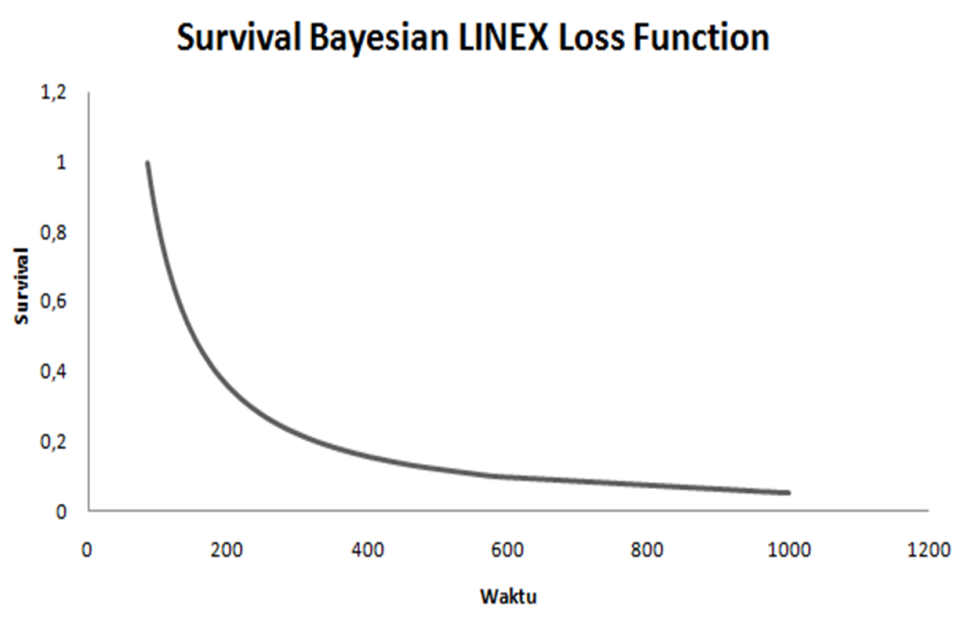

Gambar 2 Grafik fungsi survival dengan metode Bayesian LINEX Loss Function

Dari Gambar 1 dan Gambar 2 terlihat bahwa grafik fungsi survival dan grafik fungsi survival dengan metode Bayesian LINEX Loss Function semakin lama semakin menurun mendekati 0 yang berarti peluang seseorang untuk mengalami kematian lebih tinggi. Tetapi pada Gambar 1 dan Gambar 2 memiliki perbedaan yaitu dapat dilihat dari hasil estimasi, jika diambil sebarang nilai $t_{i}$ pada data kasus penderita kanker paru-paru dengan $t_{1}=87, t_{2}=118, t_{3}=200, t_{4}=384$, dan $t_{5}=999$ maka dapat diketahui peluang individu dapat bertahan hidup sebagai berikut:

Tabel 2 Hasil perhitungan Fungsi Survival dan Fungsi Survival dengan Metode Bayesian LINEX Loss Function

\begin{tabular}{|c|c|}
\hline Survival Pareto & Survival Bayesian LINEX Loss Function \\
\hline$S(87 ; 72)=0,7987139$ & $\hat{S}_{B L}(87 ; 83,57)=0,953369919$ \\
\hline$S(118 ; 72)=0,556149$ & $\hat{S}_{B L}(118 ; 83,57)=0,663836838$ \\
\hline$S(200 ; 72)=0,297197$ & $\hat{S}_{B L}(200 ; 83,57)=0,354743672$ \\
\hline$S(384 ; 72)=0,1369566$ & $\hat{S}_{B L}(384 ; 83,57)=0,163475655$ \\
\hline$S(999 ; 72)=0,0439979$ & $\hat{S}_{B L}(999 ; 83,57)=0,052517225$ \\
\hline
\end{tabular}

Dari hasil Perhitungan Fungsi Survival dan Fungsi Survival dengan Metode Bayesian LINEX Loss Function dapat dilihat perhitungan peluang hidup pada kasus kanker paru-paru menjadi lebih tinggi.

\section{Perhitungan Nilai MAPE}

Mean Absolute Percentage Error (MAPE) merupakan pengukuran kesalahan yang menghitung ukuran persentase penyimpangan antara data aktual dengan data peramalan[8]. Mean Absolute Percentage Error (MAPE) dihitung dengan menggunakan kesalahan absolut pada tiap periode dibagi dengan nilai observasi yang nyata untuk periode itu. Kemudian, merata-rata kesalahan persentase absolut tersebut. Nilai MAPE dapat dihitung dengan persamaan berikut:

$$
M A P E=\frac{\sum(S-\hat{S}) / S}{n} \times 100
$$

Dimana $S$ merupakan data awal survival, $\hat{S}$ merupakan data survival yang sudah di estimasi dan $n$ adalah jumlah data dengan syarat $t>\theta$. 
Kriteria nilai MAPE jika dilihat dengan tabel adalah sebagai berikut:

Tabel 3 Kriteria MAPE

\begin{tabular}{|l|l|}
\hline MAPE & Status \\
\hline$<10 \%$ & Sangat Baik \\
\hline $10 \%-20 \%$ & Baik \\
\hline $20 \%-50 \%$ & Cukup \\
\hline$>50 \%$ & Buruk \\
\hline
\end{tabular}

Berdasarkan persamaan (17) diperoleh nilai MAPE sebagai berikut:

$$
M A P E=\frac{12,5860378}{64} \times 100=19,66 \%
$$

\section{KESIMPULAN}

1. Estimasi parameter model survival berdistribusi Pareto pada data tersensor menggunakan metode Bayesian LINEX dengan distribusi posterior Gamma adalah sebagai berikut:

$$
\begin{aligned}
& \hat{S}_{B L}\left(t_{i} ; \hat{\theta}_{B L}\right)=\left(\frac{-\frac{1}{C}(A+n \alpha \ln B-A \ln (B+c)-n \alpha \ln (B+c))}{t}\right)^{\alpha} \\
& \hat{h}_{B L}\left(t_{i} ; \hat{\theta}_{B L}\right)=\frac{\alpha}{t}
\end{aligned}
$$

2. Berdasarkan hasil estimasi metode Bayesian LINEX untuk studi kasus kanker paru-paru dapat diketahui peluang seorang individu untuk bertahan hidup semakin lama semakin kecil (mendekati nol), hingga akhirnya mengalami kematian. Dan berdasarkan grafik Fungsi Survival Pareto dan grafik Fungsi Survival dengan Metode Bayesian LINEX Loss Function yaitu perhitungan peluang hidup sesorang penderita kanker paru-paru menjadi lebih tinggi.

3. Nilai MAPE yang diperoleh dari fungsi Survival distribusi Pareto dengan pendekatan Bayesian LINEX Loss Function adalah sebesar 19,66\%. Hal ini berarti bahwa metode Bayesian LINEX Loss Function memiliki kemampuan peramalan yang baik dalam mengestimasi peluang hidup pasien penderita kanker paru-paru.

\section{DAFTAR PUSTAKA}

[1] Kleinbaum, D.G., and Klein, M. Survival Analysis : A Self-Learning Text Second Edition, Springer Science Business Media, Inc, New York, 2005.

[2] Guure, C.B., and Ibrahim, N.A., Bayesian Analysis of the Survival Function and Failure Rate of Weibull Distribusion with Cencored Data. Journal Mathematical Problems in Engineering, Vol 2012, Article ID 329489, 2012.

[3] Ni'mah, R, and Agoestanto, A. Estimator Bayes Untuk Rata-Rata Tahan Hidup Dari Distribusi Rayleigh Pada Data Disensor Tipe II. UNNES Journal of Mathematics, 3;2., 2014.

[4] Lawless, J.F. Statistical Models and Method for Lifetime Data Second Edition, John Wiley \& Sons Inc, New York, 2003.

[5] Bain, L.J. and Engelhardt, M. Introduction to Probability and Mathematical Statistics, Ed ke-2, Duxbury of Wathfor,Inc., California, 1992.

[6] Pu, C. dan Pan, X. On The Actuarial Simulation of The general Pareto Distribution of Catastrophe Loss, Lecture Notes in Electrical Engineering, 2013. 
[7] Jamilah, Firdaus \& Sugiarto, S. Penduga Interval Parameter Bentuk Dari Distribusi Pareto Berdasarkan Metode Momen Dan Maksimum Likelihood. Fakultas Matematika Dan Ilmu Pengetahuan Alam Universitas Riau.Pekanbaru, 2007.

[8] Pakaja, F., Naba, A., Purwanto. Peramalan Penjualan Mobil Menggunakan Jaringan Syaraf Tiruan dan Certainty Factor, Jurnal EECCIS, Vol.6, No.1, Juni 2012.

MEGA PUTRI

SHANTIKA MARTHA

SETYO WIRA RIZKI
: JurusanMatematika FMIPA UNTAN, Pontianak mega13@student.untan.ac.id

: JurusanMatematika FMIPA UNTAN, Pontianak shantika.martha@math.untan.ac.id

: JurusanMatematika FMIPA UNTAN, Pontianak

setyo.wirarizki@math.untan.ac.id 